\title{
A survey of female prostitutes at risk of HIV infection and other sexually transmissible diseases
}

\author{
C R Philpot, C L Harcourt, J M Edwards
}

\begin{abstract}
Objective-To determine risk factors for the transmission of human immunodeficiency virus (HIV), including injecting drug use (IDU), sexual behaviour and other sexually transmissible diseases (STDs), in female prostitutes who attended the Sydney Sexual Health (previously STD) Centre.

Design-We surveyed by questionnaire 231 $(47 \%)$ of 491 female prostitutes who visited the Centre over a 19 month period from 1986 to 1988. All were tested for HIV antibody.

Main outcome-All the women were seronegative for HIV but a number of major risk factors for infection were identified.

Results-Seventeen of $26(65 \%)$ current injecting drug users had shared needles in the previous 6 months. Nineteen per cent of those surveyed had bisexual non-paying partners and $21 \%$ had partners who injected drugs. Sixty nine per cent always used condoms for vaginal intercourse with paying clients, but they were rarely used with non-paying partners. Condom use was also rare for anal intercourse with clients and/or partners by those $(18 \%)$ who practised it. Seventeen per cent used condoms alone for contraception and $48 \%$ relied on oral contraceptives. We found a reduction in gonorrhoea, herpes and trichomoniasis when compared with a 1985 study conducted at the same Centre. However, there was an increase in reported abnormal cervical cytology.

Conclusion-In spite of behaviour change by some, there are still many women working as prostitutes in Sydney who remain seriously at risk of HIV infection. We recommend more widespread use of barrier methods of contraception, intensified efforts to prevent the sharing of intravenous needles, closer monitoring of the health of prostitutes, and scientific study of their paying and non-paying sexual partners.
\end{abstract}

Sydney Sexual Health (previously STD) Centre, Sydney Hospital, Macquarie Street, Sydney, NSW 2000, Australia

C R Philpot, C L Harcourt, J M Edwards

\section{Introduction}

For the purpose of this study we have defined "prostitute" as a person who provides sexual services for money or other material gain. Sexual services do not always include penetrative sexual intercourse, but for nearly all the women we interviewed this was the most common service offered to clients. All the women identified themselves as professional "workers" (prostitutes).

We previously published a survey of 132 female prostitutes and 55 non-prostitutes who were interviewed at Sydney STD Centre in $1985 .{ }^{1}$ None of the women at that time was infected with the human immunodeficiency virus (HIV) but the prostitutes in particular had a number of behavioural and other factors which placed them at increased risk of HIV infection. These included a high rate of infection with other sexually transmissible diseases (STDs), injecting drug use (IDU), and having unprotected sexual intercourse with partners at high risk of HIV infection through IDU and/or bisexual behaviour. In the intervening years the heterosexual spread of HIV infection in Australia has been slow, and by the time of writing, there has been no documented case of a female prostitute in Australia becoming infected with HIV through sexual intercourse. ${ }^{23}$

Globally, studies of female prostitutes continue to show wide variation in the prevalence of HIV infection. In Africa, and increasingly in Asia, female prostitution is a major conduit for transmission and a high proportion of prostitutes are infected. ${ }^{4-6}$ In Australia, most of Europe, and the UK, HIV infection in female prostitutes is mainly IDU related and has shown little tendency to spread beyond identified high risk groups. ${ }^{78}$ HIV prevalence rates in female prostitutes are higher in the USA, but vary greatly from one locale to another. ${ }^{9}$ While risk levels vary with socio-economic status and racial background, there is still a strong association between IDU, prostitution and HIV infection in that country..$^{10}$ Many women who have become infected have sexual partners who are injected drug users. ${ }^{11}$

A recent review of the literature on women and HIV makes three major points. ${ }^{12}$ These are: (1) worldwide the vast majority of AIDS cases arise from heterosexual transmission; (2) in the non Westernised world women and men are infected in almost equal numbers, while in the West women represent an increasing proportion of new cases; and (3) there is 
some evidence that transmission occurs more readily from men to women than vice versa. Co-factors for transmission to women include, other STDs, anal intercourse, and possibly the use of the oral contraceptive pill (OCP). ${ }^{12}$

Between December 1986 and June 1988 we conducted a longitudinal study of female prostitutes attending our Centre, using a modified form of the questionnaire first employed in $1985 .{ }^{1}$ We aimed to collect demographic and behavioural data, document infection with HIV and other STDs, identify risk factors for infection, and assess responses to "safer sex" information offered through peer and public education and through the Centre.

\section{Subjects}

We enrolled 231 women between 1986 and 1988, who attended the Centre for routine medical checks. Criteria for eligibility were that the subject was known to be working as a prostitute, could speak and understand English (a separate study of non Englishspeaking prostitutes was also conducted and will be reported separately), and gave informed consent. A total of 491 female prostitutes attended the Centre during this period. All were tested one or more times for HIV and none was found to be positive. While our sample comprised $47 \%$ of female prostitutes attending the Centre, it is not known how many were ineligible for the study because of language difficulties. As a State Reference Centre the Sexual Health Centre attracts a broad cross section of patients from all suburbs of Sydney as well as from rural areas and other industrial cities.

\section{Methods}

After giving informed consent each woman was asked to respond to an administered questionnaire which contained questions on: personal details such as marital status, educational level, other forms of employment; STD and other relevant medical history; oral and injecting drug use; sexual activities including numbers of paying and non paying partners, condom use, contraception, frequency of engaging in different types of sexual activity; and work locale and number of years in prostitution. Each questionnaire took approximately 20 minutes to complete but many women offered additional information and opinions, which were also recorded on the questionnaires. Confidentiality was ensured by the use of coded identification numbers and the omission of all names and addresses from the question papers. Access to the code and to completed questionnaires was restricted to the authors who subsequently checked medical histories and personal details against the Centre's Medical Records, correcting or supplementing the data as necessary.
Each woman had requested and received an HIV antibody test prior to being enrolled in the study, but generally not on the same day as the questionnaire. Nearly all the women knew the result of their most recent test at the time of interview.

\section{Laboratory analysis}

Serum was tested for antibodies to HIV by an enzyme linked immunosorbent assay (ELISA) (Electronucleonics, Columbia, Maryland, USA).

\section{Results \\ Age}

The majority (132 [57\%]) of prostitutes in this sample were aged between 20 and 29 years. The mean age was $28 \cdot 3$ years (SD 6.6), range 16 to 54 years. There were 12 teenagers, 76 aged 30 to 39 and 11 aged 40 to 45 .

\section{Work locale}

The prostitutes in our survey came from a wide variety of socio-economic backgrounds and lived and worked in a variety of locales throughout the metropolitan area and beyond. Most (131 [57\%]) worked in brothels (known locally as parlours) of which only four came from outside the metropolitan area. Of the remainder, $22(10 \%)$ worked privately, $16(7 \%)$ were escorts, four worked from the streets and four were in the process of changing their workplace. One woman worked in a bondage and discipline establishment within a brothel. Information about the workplace was not recorded for 53 $(23 \%)$ of the sample.

\section{Drug use}

The drugs used by most women in the previous six months were marihuana (127 [45\%]), sleeping pills $(48[20 \%])$, cocaine $(42[18 \%])$, amphetamines (39 $[17 \%])$, heroin $(23[10 \%])$, methadone $(6[3 \%])$, and tranquillisers and antidepressants $(33[14 \%])$. Only one reported using crack. Seventy eight (34\%) recorded no illicit or prescription drug use in the previous six months.

In response to questions about lifetime IDU and needle sharing, $51(22 \%)$ had at some time injected, of whom $31(61 \%)$ had sometimes shared needles. Twenty six $(11 \%)$ had injected drugs within the previous six months with $17(65 \%)$ of these having shared at least once during that period.

Lack of needles and convenience were given as the reasons for sharing by $29(94 \%)$ of the women who had ever shared. When those who had ever injected were asked if they would share needles and syringes in the future, $45(88 \%)$ said they would not, one said "possibly", three "probably", and two "very likely".

Fewer women who admitted sharing injecting equipment were enrolled in the later part of this 
Table 1 Use of condoms for vaginal intercourse by 231 female prostitutes; 1986-88

\begin{tabular}{lcl}
\hline $\begin{array}{l}\text { \%occasions } \\
\text { using condoms }\end{array}$ & $\begin{array}{c}\text { With paying clients } \\
\text { No (\%) prostitutes }\end{array}$ & $\begin{array}{l}\text { With non-paying } \\
\text { partners } \\
\text { No }(\%) \text { prostitutes }\end{array}$ \\
\hline 0 & $6(3)$ & $156(68)$ \\
$1-20$ & $14(6)$ & $2(1)$ \\
$21-40$ & $8(4)$ & $1(-)$ \\
$41-60$ & $7(3)$ & $2(1)$ \\
$61-80$ & $23(10)$ & $2(1)$ \\
$81-99$ & $13(6)$ & $1(-)$ \\
100 & $160(69)$ & $27(12)$ \\
& 231 & $191 \star$
\end{tabular}

$\star$ Forty $(17 \%)$ women did not complete this question because they had not recently had a sexual relationship with a non paying male partner.

study. The drug use of the first 150 women enrolled in $1986 / 87$ is reported in detail elsewhere and shows that 15 of $17(88 \%)$ current drug users shared needles. ${ }^{13} \mathrm{~A}$ further 81 women were interviewed in 1988 , bringing the total to 231 , and of these only two of nine $(22 \%)$ current users shared needles.

Alcohol and tobacco use by the first 150 women enrolled is also reported elsewhere and reveals a higher than average level of tobacco consumption by female prostitutes compared with other women, and a dangerously high alcohol consumption by a small minority of the prostitutes interviewed. ${ }^{13}$

\section{Number of sexual partners}

The reported number of paying clients in the week prior to interview ranged from nought to 100 (median 17.5). One hundred and fifteen (50\%) women reported between 11 and 30 clients per week. Fifteen $(7 \%)$ reported $31-40$ clients and nine $(4 \%)$ reported 41 to 100 per week. Thirty two women $(14 \%)$ were not working during this time, for a variety of health and social reasons.

The lifetime number of male non-paying sexual partners ranged from nought to 60 (median 16.5). Forty four $(19 \%)$ of the women thought at least one of their non-paying partners was bisexual and 48 $(21 \%)$ reported non-paying partners who injected drugs.

\section{Condom use}

Nearly all the prostitutes engaged in oral and vaginal sex with their clients. A majority (160/231-69\%) used condoms all the time for vaginal sex (table 1) but less than half of this number $(75 / 231-33 \%)$ used condoms for oral sex as well.

Most women reported that they would not engage in anal sex with clients, many giving as a reason the risk of HIV infection. Nevertheless $21(9 \%)$ women said they did sometimes engage in anal intercourse with clients and three of these said they did so frequently. Fourteen of the 21 never used condoms for anal sex and only one used a condom on each
Table 2 Sexually transmissible diseases (STDs) of female prostitutes in previous 5 years; 1985 compared with 1986-88

\begin{tabular}{llc} 
& \multicolumn{2}{l}{$\begin{array}{l}\text { Number (\%) of women having 1 } \\
\text { or more episodes }\end{array}$} \\
\cline { 2 - 3 } & 1985 & $1086-88$ \\
$S T D$ & $n=132$ & $n=231$ \\
\hline Gonorrhoea & $76(58)^{\star}$ & $88(38)^{\star}$ \\
Chlamydial infection & $61(46)$ & $92(40)$ \\
Pelvic inflammatory disease & $29(22)$ & $46(20)$ \\
Syphilis & $3(2)$ & $8(4)$ \\
Hepatitis B & $8(6)$ & $13(6)$ \\
Herpes & $67(51) \dagger)$ & $58(25) \dagger$ \\
Trichomoniasis & $68(52) \dagger)$ & $67(29) \ddagger$ \\
Vaginitis/cervicitis $\|$ & na & $142(62)$ \\
Genital or anal warts & $33(25)$ & $65(28)$ \\
Abnormal cervical cytology & $21(16) \S$ & $76(33) \S$ \\
HIV infection & 0 & 0 \\
No infections & na & $16(7)$ \\
\hline
\end{tabular}

$\star+\ddagger d e n o t e$ significant decreases in proportion infected in the later study.

${ }^{\star}$ Chi-squared $=8, p=<0.005$.

tChi-squared $=9 \cdot 9, \mathrm{p}=\langle 0.002$.

tChi-squared $=11, \mathrm{p}=<0.001$

$\S$ Denotes a significant increase in proportion infected in the later study.

Chi squared $=6.9, \mathrm{p}=<0.01$.

Includes thrush and non specific inflammatory conditions. In $1985,84(64)$ cases of thrush were reported.

na $=$ (data) not available.

occasion, while the remainder used condoms infrequently.

Condoms were used less often with non-paying partners. One hundred and fifty six $(68 \%)$ did not use condoms at all for vaginal sex with their private partners, and only $27 / 231(12 \%)$ used condoms all the time. The remainder used condoms occasionally. Twenty eight $(12 \%)$ practised anal intercourse with non-paying partners and none of these used condoms. Altogether $42 / 231(18 \%)$ sometimes engaged in anal sex; $14(6 \%)$ with clients only, $21(9 \%)$ with non-paying partners only, and seven $(3 \%)$ with both.

\section{STD including HIV infection}

Table 2 shows the number of women who had one or more episodes of STD in the five years prior to questioning. A comparison is made with the responses to a similar question in $1985^{1}$ and shows significant decreases in reported gonorrhoea $(p=<0.005)$, herpes $(p=<0.001), \quad$ and trichomoniasis $(p=<0.002)$, but an increase in reported abnormal cervical cytology detected on Papanicolau smear $(\mathrm{p}=<0.01)$.

In the current study $33 / 76(43 \%)$ of the cervical abnormalities were HPV related, with no complications. A further $26(34 \%)$ were due to inflammatory or other conditions, including four cases of herpes simplex virus (HSV) infection. Of concern, however were $17(22 \%)$ which revealed CIN lesions. Twelve of these were CIN 1, three CIN 2 and two CIN 3. Unfortunately comparable data are not available for the 1985 study. 
All 231 prostitutes were seronegative for antibody to HIV.

\section{Use of contraceptives}

The oral contraceptive pill (OCP) was the most favoured form of contraception for $111(48 \%)$ women. Forty (17\%) women relied on condoms with or without spermicide, $17(7 \%)$ used a diaphragm and 15 used an interuterine contraceptive device (IUCD). Of 41 (18\%) not using contraceptives 35 said they were infertile because of hysterectomy, tubal ligation, or for an unspecified reason.

IDU was identified in $22 \%$ of our sample, although it appears that only $11 \%$ were currently engaging in this behaviour. The continuing presence of this risk factor for HIV infection in 17 women is important because to date IDU appears to have been the most likely mode of transmission in a small number of known HIV infected female prostitutes in New South Wales (personal communication from the staff at the Kirketon Road Centre where many youthful infected drug users are seen, and at Albion Street (AIDS) Centre). IDU is a major mode of transmission to women in the USA ${ }^{14}$ and in some European countries. $^{7}$

Heterosexual risk in this group is largely associated with non-paying partners with whom safer sex is rarely practised. Seventy one $(31 \%)$ believed they had non-paying partners at risk through IDU and/or bisexuality and yet only $27(12 \%)$ said they would use condoms all the time in private relationships. However, $40(17 \%)$ said they used condoms as their preferred form of contraception. This apparent discrepancy may have arisen partly because not all the women using condoms for contraception had current non-paying partners and were therefore referring only to client contacts, and partly because contraception is often practised selectively and is not seen to be necessary every time intercourse occurs.

There has overall been a very big increase in condom use with paying clients since our first survey was conducted in 1985 when only $11 \%$ used condoms all the time. ${ }^{1}$ In the present study 160 of $231(69 \%)$ prostitutes used condoms for all occasions of vaginal intercourse with paying clients, and only $20(9 \%)$ used them for twenty per cent of the time or less. In $198512 \%$ did not use condoms at all, but in 1987-88 this figure was reduced to three per cent. The most dramatic increase in condom use among working prostitutes in Sydney occurred in mid 1987 shortly after the launch of a media AIDS education campaign directed at the heterosexual population, ${ }^{15}$ and after more than a year of intensive outreach work by the Australian Prostitute's Collective in conjunction with STD Centre staff. This increase in condom use with paying clients is encouraging and we have been able to link it with a reduced incidence of acute sexually transmitted diseases in some women. ${ }^{15}$
In this study also there appears to have been a decline in the prevalence of some acute STDs in female prostitutes attending the SSHC. The continuing high and even increased numbers of abnormal cervical cytologies may be explained by the long latency period of most viral conditions, and reflects an earlier pattern of sexual behaviour in those infected.

Anal intercourse had been implicated as a co-factor for the spread of HIV in homosexual and heterosexual relationships. It appears that anal intercourse is practised infrequently if at all by the great majority of female prostitutes in Sydney; however when it does occur, in spite of the general increase in condom use mentioned above, there is a marked reluctance to use them during this very high risk activity. Again the women were more likely to engage in unprotected anal intercourse with non-paying partners of whom 28 of $28(100 \%)$ "never" used condoms, than with paying clients of whom 14 of $21(66 \%)$ "never" used them.

Another possible co-factor for HIV transmission to women is the use of the OCP. ${ }^{12}$ Nearly half $(48 \%)$ our sample was using the pill as currently preferred contraception and many more had used it previously. The widespread use of the OCP since the early 1960 s has been linked with an increase in STDs as it dispenses with the need for barrier contraceptives, and it has also been linked with the occurrence of circulatory problems in older women after long term use. Given that $42(18 \%)$ women in our sample were over 36 years of age and that many of them were also heavy smokers ${ }^{14}$ there are a number of grounds for concern over the use of the pill as the contraceptive of choice by prostitutes. We strongly recommend that women working as prostitutes consider a combination of two or more barrier methods of protection (condoms, diaphragms, sponges, spermicides) as being safer long term forms of contraception.

As a group the female prostitutes we have studied are affected by all the currently recognised risk factors and co-factors for HIV infection to a greater or lesser degree. The majority of individuals are certainly not at risk on each count and while the overall level of heterosexual transmission remains low many appear to be not greatly at risk at all. Nevertheless there is a minority of female prostitutes in our sample whose lifestyles, medical histories, and sexual and needle sharing behaviour place them and their sexual partners squarely within the identified high risk groups in Australia.

It is essential to continue to monitor closely the health of women working as prostitutes, and also to collect relevant data on their sexual partners whose activities span the entire range from very high risk to very low risk of HIV infection.

This study was made possible by a grant from the New South Wales Department of Health. 


\section{Address correspondence to D C R Philpot.}

1 Philpot CR, Harcourt C, Edwards J, Grealis A. Human immunodeficiency virus and female prostitutes, Sydney 1985. Genitourin Med 1988;64:193-7.

2 National Centre in HIV Epidemiology and Clinical Research. Australian HIV Surveillance Report, October 1990;6, Supplement 2.

3 Harcourt C, Philpot R. Female prostitutes, AIDS, drugs, and alcohol in New South Wales. In: Plant M, ed. AIDS, Drugs and Prostitution. London, Routledge, 1990:139-40.

4 Simonsen JN, Plummer FA, Ngugi EN, et al. HIV infection among lower socioeconomic strata prostitutes in Nairobi. AIDS 1990;4:139-44.

5 Simoes EAF, Babu PG, John TJ, et al. Evidence for HTLV-III infection in prostitutes in Tamil Nadu (India). Indian Journal Med Res 1987;85:335-8.

6 Smith DG. Thailand: AIDS crisis looms. Lancet 1990;i:781-2.

7 Plant M, ed. AIDS, Drugs and Prostitution. London, Routledge, 1990.

8 Collaborative Study Group. HIV infection in patients attending clinics for sexually transmitted diseases in England and Wales. BMJ 1989;298:415-8.
9 Darrow W. Prostitution, intravenous drug use, and HIV-1 in the United States. In: Plant M. ed. AIDS, Drugs and Prostitution. London, Routledge, 1990:28-33.

10 Centers for Disease Control. Antibody to human immunodeficiency virus in female prostitutes. Morbidity and Mortality Weekly Report, 1987;36:157-61.

11 Curran JW, Jaffe HW, Hardy AM, Morgan WM, Selik RM, Dondero TJ. Epidemiology of HIV infection and AIDS in the United States. Science 1988;239:610-6.

12 Bradbeer C. Human immunodeficiency virus and its relation to women (Editorial Review). International Journal of STD and AIDS 1990;1:233-8.

13 Philpot CR, Harcourt CL, Edwards JM. Drug use by prostitutes in Sydney. British Journal of Addiction 1989;84:499-505.

14 Rosenberg MJ, Weiner JM. Prostitutes and AIDS: a health department priority? Am J Public Health 1988;78:418-23.

15 Harcourt C, Philpot R, Edwards J. The effects of condom use by clients on the incidence of STDs in female prostitutes. Venereology 1989;2:4-7.

Accepted for publication 3 June 1991. 